\title{
Predatory strike of the tentacled snake (Erpeton tentaculatum)
}

\author{
Tamara L. Smith ${ }^{1}$, G. David E. Povel ${ }^{2}$ and Kenneth V. Kardong ${ }^{1 *}$ \\ ${ }^{1}$ School of Biological Sciences, Washington State University, Pullman, WA 99164-4236, U.S.A. \\ ${ }^{2}$ Evolutionary Morphology Section, Institute of Evolutionary and Ecological Sciences, Rijksuniversiteit te Leiden, Kaiserstraat 63, Postbus \\ 9516, 2300 RA Leiden, Netherlands \\ (Accepted 27 February 2001)
}

\begin{abstract}
The tentacled snake Erpeton tentaculatum lives its entire life in fresh water where it feeds mostly on fish. Because the tentacled snake strikes underwater, the physical demands differ from those of air, and require modified methods of prey capture compared to terrestrial snakes. To examine this, we scored the feeding behaviours of five snakes and used multiple high-speed films of two snakes striking fishes. In the pre-strike phase, the snake usually assumed a J-shaped posture with its head turned posteriorly at the neck and its body held straight. The snake waited in such a rigid posture for the fish to move into the very narrow 'window' between turned head and body. Tentacles remained erected, and motionless. The strike was extremely rapid, occurring typically from pre-set J-shaped postures, not from sigmoidal body coils. As the head turned and travelled to the fish, the mouth opened and water collected in the ballooning throat. Significant suction feeding was absent. The fish was secured on buccal teeth and quickly swallowed by unilateral displacements of the jaws. Prey capture and swallowing exhibited specialized modifications of the general snake predatory behaviour to address the hydrodynamic demands of such an underwater strike.
\end{abstract}

Key words: snake feeding, biomechanics, feeding behaviour, Erpeton

\section{INTRODUCTION}

The tentacled snake Erpeton tentaculatum lives its entire life in fresh water feeding on aquatic organisms, principally fish (E. H. Taylor, 1965). It occurs in slow-flowing streams or sluggish ponds (Smith, 1943). A pair of fleshy tentacles reside at the anterolateral corners of the snout, which, when submerged, project forward, and give the snake its common name. Because it strikes underwater, the tentacled snake, like other aquatic feeding organisms, experiences physical demands that are different from air (Liem, 1990), and that may require modified methods of prey capture compared to terrestrial snakes. M. A. Taylor (1987) explored these consequences of aquatic feeding upon the structure of the head, neck, and teeth of tetrapods generally. Among his predictions were that prey size was likely to affect swallowing. Small prey tend to be swallowed underwater, large prey above with assistance of gravity, inertial feeding, and tongue (intra-oral transport).

*All correspondence to: Dr. K. V. Kardong.

E-mail: kkardong@wsu.edu
Within aquatic snakes, most comments upon feeding attributes have been parts of reports on diet or ecology (Fitch, 1949, 1965; Gillingham, 1974; Mushinsky \& Hebrard, 1977; Shine, 1977, 1986; Gregory, 1978; Voris, Voris \& Lim, 1978; Madsen \& Osterkamp, 1982; Voris \& Voris, 1983; Jayne, Voris \& Heang, 1988). Brief reports characterizing the measurements of physical forces on feeding behaviour of aquatic snakes are available (Braun \& Cundall, 1995; Alfaro, 1998). Across various snake clades, aquatic species have been observed to catch fish by holding the mouth open and sweeping the head from side to side while actively moving through the water; natricines, (Drummond, 1983; Halloy \& Burghardt, 1990); homalopsines (Jayne et al., 1988); hydrophiines, (Heatwole, 1987); elapids, (Kropach, 1975; Voris et al., 1978); viperids, (Savitzky, 1992). Such mouth-open side sweeping might reduce drag (Braun \& Cundall, 1995) or reduce production of bow waves that precede the approaching strike. However, only Young (1991) has treated this in depth, providing theoretical analysis, testing, and predictions upon performance of aquatic feeding snakes. In particular, he notes that a rapid strike in aquatic snakes may 
minimize drag in several ways: lateral strike ( $v s$ frontal); low head profile (dorso-ventrally compressed). Further, the low mass of the striking region of the snake reduces the forces necessary to produce head acceleration.

The tentacled snake differs from most other aquatic feeding snakes in that it does not catch prey while actively moving through the environment, nor does it sweep an open mouth back and forth waiting to come in contact with prey. During initial observations of feeding, it was noted that tentacled snakes did not satisfy paradigm predictions of swallowing (e.g. M. A. Taylor, 1987), but did incorporate a suite of hydrodynamic predictions (e.g. Young, 1991) into a unique strike behaviour producing remarkably fast acceleration underwater. Also, some of its specialized features, i.e. prehensile tail and cephalic tentacles, did not participate in the strike. Our goals were: (1) to characterize the unusual feeding behaviour of the tentacled snake; (2) to describe kinematic and dynamic events of the rapid strike itself through analysis of high-speed sequences; (3) to examine the post-strike swallowing behaviour of the snakes, especially as it relates to prey size.

\section{MATERIALS AND METHODS}

\section{Subjects}

Qualitative and kinematic data were obtained from 5 captive-bred tentacled snakes Erpeton tentaculatum supplied by the Fort Worth Zoo. Four of the snakes were small (17.0-25.8 cm snout-vent length (SVL)), and in captivity for $>6$ months; the fifth was large $(40.2 \mathrm{~cm}$ SVL), and in captivity $>3$ years. The reptile room was kept warm all year $\left(27-32^{\circ} \mathrm{C}\right)$ on a $12: 12 \mathrm{~h}$, light/dark cycle. Each snake was housed individually in a glass terrarium c. $50 \times 50 \times 90 \mathrm{~cm}$, with rocks resting on the bottom. All were fed live goldfish on an irregular schedule. The depth of the water was maintained at $6-12 \mathrm{~cm}$. Access to the room was limited to authorized personnel familiar with the experiments and safety procedures (Gans \& Taub, 1964). All behavioural observations were based on all 5 snakes. The descriptive statistics are based on the 4 small snakes, and the strike kinematics on 1 small and 1 large snake, with rationales as given below.

\section{Filming conditions}

Using Eastman ektachrome film type 7250, the largest and 2 of the smaller snakes were filmed individually at 500 frames per second with a $16 \mathrm{~mm}$ Hycam high-speed camera with timing light and illuminated by a pair of tungsten filament photo flood lamps. The day before filming, the snake in its aquarium was placed before the camera, and a front-surfaced mirror tilted $45^{\circ}$ lowered into the water with the snake. This permitted filming of simultaneous lateral and dorsal views of the strike (Fig. 1). On the day of filming, a goldfish Carassius auratus (c. $3 \mathrm{~cm}$ snout-tail notch) was placed in the water with the snake. The lights were turned on and if the snake showed an interest in the goldfish, the camera was triggered and the ensuing strike filmed. Of the 20 strikes that were filmed, 10 included misses or were incomplete because points of interest were outside the frame. These were useful for qualitative evaluation of the strike.Ten complete strike sequences were obtained from 1 small $(n=4)$ and 1 large $(n=6)$ snake. The $x$-axis of the Cartesian coordinate system was defined as parallel to the line of travel of the snake's head, and the other 2 axes were placed at right angles to it and each other. These sequences were analysed frame-by-frame using a Selecta-frame projector, and traced sketches made of body and jaw motions. Selected points on the head, neck and body of the snake were digitized using a Summagraphs digitizing tablet, Easydig ${ }^{\mathbb{B}}$ software, providing sequential coordinate values for each point. These kinematic values were analysed using the smoothing/dynamic equations of Lancos (see Alexander, 1983) following methods detailed elsewhere (Kardong \& Bels, 1998).

\section{Definition of strike and swallowing behavioural variables}

After taking a breath at the surface, each snake submerged, and assumed a settled position from which the strike ensued. Occasionally, the strike was directly forward, but more commonly its anterior body was turned into a $\mathbf{J}$-shape, from which it struck.

When a snake had settled into such a pre-strike posture, 1 live goldfish was introduced by net at a point in the aquarium furthest from the head of the snake. The observer, with a score sheet in hand, recorded 4 variables during each strike:

posture: the strike posture assumed (J-right, J-left, straight, head in line with the body);

strike direction: to right, left, or straight forward;

strike success: missed or capture;

site: placement of the strike on the fish, i.e. head (skull including opercular cover), body (all of the fish posterior to the opercular cover up to mid-body), and tail (midbody, the widest part of the fish, to and including the caudal fin).

The observer was careful to minimize movements around the snake. All 5 snakes proved remarkably tolerant of disturbance, even striking live fish immediately as they were presented (outside these experimental trials) after handling when aquarium water was changed during routine husbandry.

In addition to these variables, 4 post-strike variables were scored.

Handling time: the time (s) from the end of the strike until swallowing began.

Swallowing time: the time (s) from onset of unilateral jaw displacements along the long axis of the fish (sensu Kardong, 1986) until the very last part of the fish (always the tip of the caudal fin) entered the mouth as seen in direct dorsal view. 
Prey size: defined as the fish length from mouth to tail notch, a dimension within a species highly correlated with width and mass (Mori, 1998). To find out the upper limit of prey size and to examine the effects of prey size on feeding, the size of fish presented was gradually increased until the snakes no longer struck or ceased swallowing the captured fish and released it.

Swallowing orientation: whether swallowing was head or tail first.

The 4 small snakes, because they were about the same size, were used to gather summary statistics on how they responded to large prey, reaching the maximum size they could catch and swallow.

\section{RESULTS}

\section{Feeding episode}

The natural predatory behaviour of a snake may include distinct behavioural patterns that precede the strike, and several others that follow (Cock Buning, 1983; Hayes, 1991). Our analysis included the preparatory phase of the pre-strike phase, the brief strike itself, and the post-strike phase. The strike phase included three stages, all of which were preceded by the preparation phase.

\section{Preparation phase}

All five snakes exhibited similar use of body postures and general predatory behaviour. Periodically $(c$. every $20 \mathrm{~min}$ ), the undisturbed snake characteristically tilted its anterior body to the surface, occasionally securing a hold posteriorly with its prehensile tail, and allowed its head to break the surface enough to protrude the dorsally placed nostrils above the water. Often the whole head emerged completely from the water and the tentacles fell limp back across the sides of the snout. In this partial or complete head emersion position, the snake vented and filled its lungs several times, then re-submerged reaching a position with its head $3-4 \mathrm{~cm}$ below the water surface. Submerged, its prehensile tail was often, but not always, around objects within the aquarium, its body was rigid and held mostly straight, and its head turned posteriorly thereby forming a J-shaped bend in the neck region. It was from such a posture, not from reversing body coils (e.g. rattlesnake, Kardong \& Bels, 1998), that a predatory strike most commonly ensued. When the snake was submerged, the tentacles projected at about $45^{\circ}$ from the corners of the snout. They exhibited no motion or undulations even when the live fish was close to the head. When the natural movement of the fish brought it near the poised snake, the snake raised or lowered its vertical body position within the water column or it slightly opened or tightened the J-shaped posture. However, a snake held its position, sometimes for 20-30 min, waiting for the fish to move to the inside bend defined by the pre-set J-shape curve in its neck. Often the fish moved close to or actually touched the top of the head, or it moved along the outside curvature of the neck. The snake did not usually strike with the fish at these locations. Even when the fish was within the inside bend, the snake typically waited until the fish was turned with its head facing the snake (e.g. Fig. 1a). Only as the fish moved to a location within the neck bend, head-to-head, did the snake strike.

\section{Strike phase}

\section{Extend}

During the strike phase, the head moved posteriorly relative to the body from the J-shaped posture. The jaws rapidly parted producing a widening buccal gape brought over the fish. This gape resulted from depression of the lower jaws (up to $20^{\circ}$ ) as well as by significant (up to $45^{\circ}$ ) uplifting of the braincase about a point of rotation in the neck that carried the suspended upper jaws into an elevated position. Jaw opening was asymmetrical. The mandible on the side of the snake closest to the fish began depression slightly before its partner of the opposite side. The tentacles began to collapse back over the head as soon as it began to accelerate toward the prey (Fig. 1b). Although the entire body lifted from its rest position, the apparent result of reaction forces from the strike, the body did not change significantly from its linear posture. Rather, the bend in the neck moved posteriorly carrying the head on a trajectory toward the fish. Consequently, acceleration of the head depended upon the neck bend, not body curves. Early in the extend stage, the glottis was in the dorsal internal nares, where it had presumably been inserted earlier during respiration, but within a few frames $(0.004 \mathrm{~s})$ it was abruptly withdrawn and brought to the floor of the buccal cavity as the lower jaws began their depression (Fig. 1c). The head, facing laterally to the prey at the onset of the strike, began to turn so that just before contact, the nearly full frontal profile of the gape closed on the prey. Concurrently with head turning, the throat began to inflate and fill with water. Both upper (maxilla) and lower (dentary) jaws were protracted and their anterior ends extended out of the mouth (Fig. 1d).

This is also illustrated in a separate sequence when a favourable direct angle of the head to the camera permitted the quantification of strike events (Fig. 2). Note that as the snake approached the prey, the lower jaw dropped significantly as the head sped to the prey.

Note also (Fig. 3) that before contact, the fish drifted horizontally, along the $x$-axis (fish $(x)$ ) but exhibited no sudden displacements as would be expected if suction were produced by the expanding oral cavity. Consequently, although the prey initiated an escape response as the jaws made contact, there was, up to that point, no evidence that the fish was drawn by negative pressures (i.e. suction feeding) toward the approaching open jaws of the snake. Instead, the jaws of the snake moved over a more or less stationary prey. 
(a)

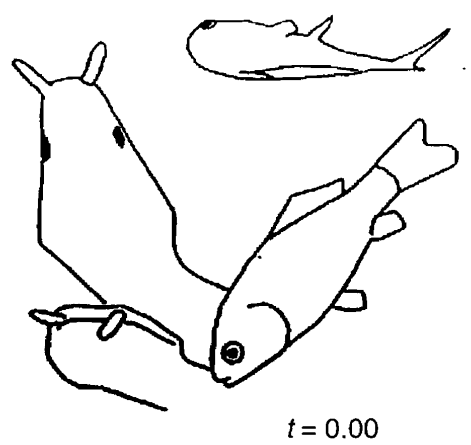

(b)

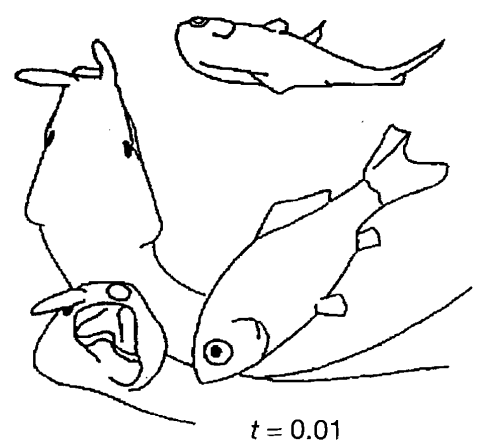

(c)

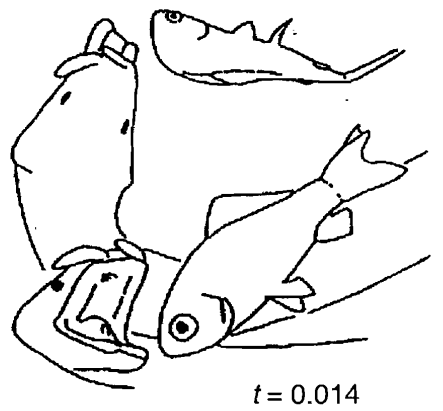

(d)

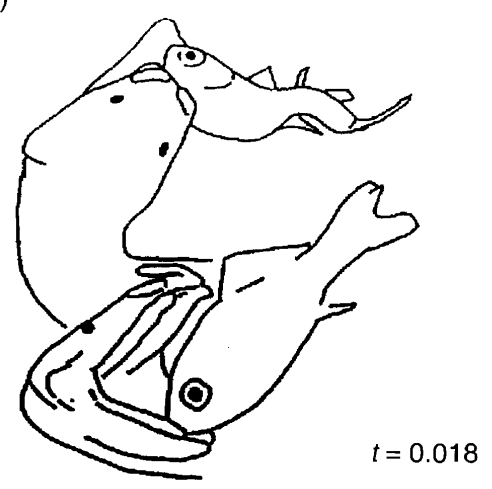

(e)

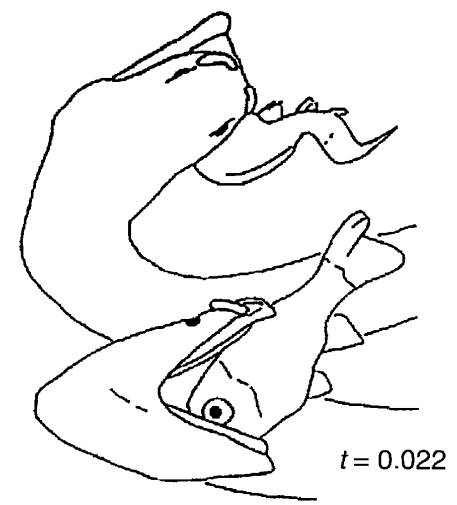

(f)

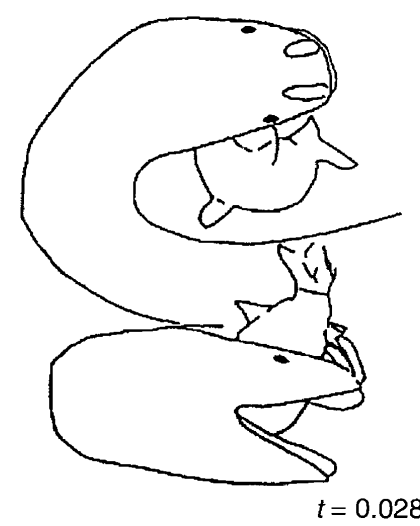

Fig. 1. Representative strike sequence. A mirror at a $45^{\circ}$ angle was placed behind the snake to provide a dorsal as well as lateral view of the strike. (a)-(f) Tracings directly from the high-speed film. (a) Strike begins, $t=0.00 \mathrm{~s}$, with snake in J-posture; (b) left mandible begins depression slightly before right mandible; (c), (d) head turns and approaches fish; (e) head makes contact as throat 'balloons' with engulfed water; (f) jaws close. $t$, elapsed time (s). Film catalogue KVK 335.1.

The expanding floor of the buccal cavity (Fig. 1d-f) is compared graphically (Fig. 2) to other events. It continues to inflate (Fig. 3, cross-hatch) through contact.

\section{Contact stage}

Both jaws moved over the fish and were closed to engage the prey, thereby establishing contact. Just before the jaws closed to engage the fish, the snout of the fish hit the floor of the buccal cavity just posterior to the tips of the mandibles. Immediately the braincase was lowered closing the jaws and engaging more posterior teeth within the mouth to secure the fish (Fig. 1e). The lower jaw usually moved under the fish before it made contact first with the fish, followed by upper jaw contact. 

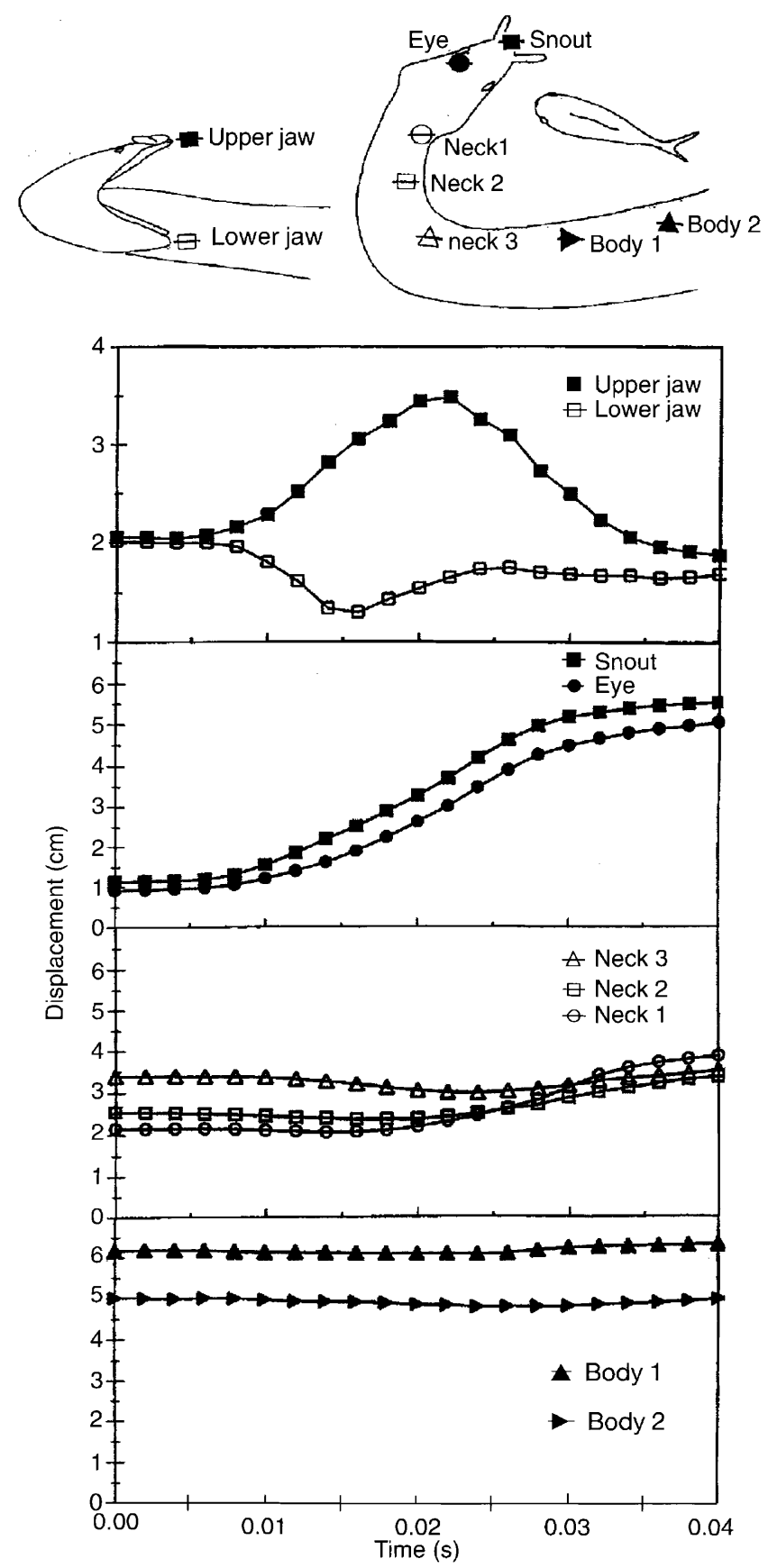

Fig. 2. Representative kinematic profiles of displacement points on the snake. The displacements are in the $x$-axis, toward the prey. Gape is plotted in the $y$-axis, vertically, showing displacements of points on the anterior tips of the upper jaw (maxilla) and lower jaw (dentary).

\section{Completion stage}

After contact with the prey and secure engagement of the many fine teeth, the inflated throat region began to decrease within $0.01 \mathrm{~s}$, until it again assumed a taut fit across the throat. Deflation and expelling of water seemed to be the result of passive recoil of the integument within the throat (Fig.1f).

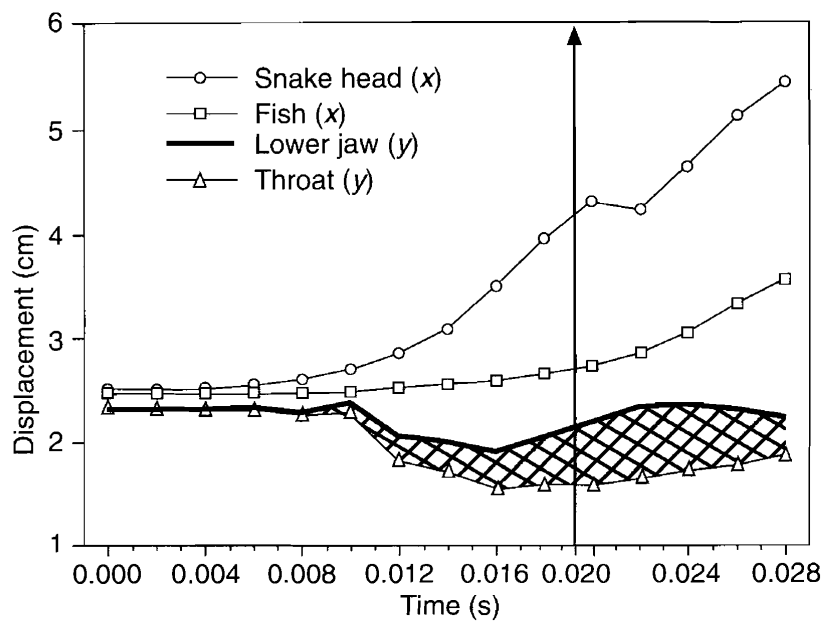

Fig. 3. Representative displacements of jaw elements during a strike. Displacements begin with first evidence of motion in the head of the snake. The point of contact with the fish is indicated by the vertical arrow. The shaded region represents the inflation of the throat relative to the lower jaw. Directions of displacements, vertical $(y)$ or horizontal $(x)$ relative to the prey are indicated.

\section{Strike statistics}

Because they were of about the same size, the four small snakes were used to collect summary statistics on the strike, each run in 12 trials producing 48 in total. Strikes were predominantly to the head $(81.2 \%, 39 / 48)$, compared to strikes to the body $(18.8 \%, 9 / 48)$ and tail $(0 \%$, $0 / 48)$ of the fish. Snakes usually missed several times $(x=4.3)$ before a successful strike, i.e. those in which the fish was caught. Successful strikes were predominantly in the same direction as the pre-set posture $(98 \%)$. Initial strike posture was about evenly divided between $\mathrm{J}$-left $(n=20)$ and J-right $(n=28)$, although this changed slightly following missed strikes, so that eventually successful strikes were from a J-left $(39.5 \%, n=19)$, J-right $(58.3 \%, n=28)$, and one $(2.2 \%)$ from a straight posture.

The distance to the prey just before (frame before) head acceleration began was measured from high-speed films of successful captures. This distance was from snout tip (between tentacles) to the closest part of the prey. The small snakes averaged $1.62 \mathrm{~cm}$ (range $0.8-3.0 \mathrm{~cm}, n=8$ strikes).

\section{Strike kinematics}

Displacements of selected body points are shown in Fig. 4. Note that points on the body remained essentially stationary, whereas the points on the neck, and especially on the head, moved significantly. Vector displacements of selected sites on the body confirm that the movement of the head to the prey involved substantial displacement of the neck (Fig. 4). The rigid body served as a relatively fixed platform from which the tightening of the neck bend drew the head to the prey. The 

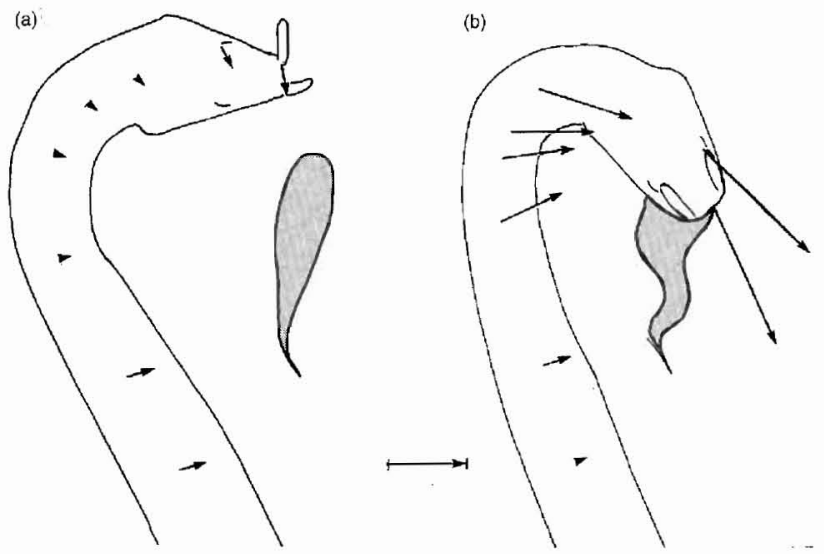

Fig. 4. Vector displacements for selected points on the snake: (a) early in the strike $(t=0.01 \mathrm{~s})$; (b) at contact $(t=0.02 \mathrm{~s})$. Arrow direction and length, resultant velocity vectors calculated over the preceding $0.01 \mathrm{~s}$. Dorsal view, with the fish shaded. Calibration vector $=100 \mathrm{~cm} \mathrm{~s}^{-1}$.

prehensile tail, when wrapped around an object, helped hold the body steady. Even when the tail was not engaged, the body still moved relatively little during the actual strike. Inertia was sufficient to keep the body relatively fixed during the strike.

Calculated accelerations of the snout indicate an average peak acceleration of $23444.1 \mathrm{~cm} \mathrm{~s}^{-2}(n=7$, range $=15 \quad 347.8-30442.2 \mathrm{~cm} \mathrm{~s}^{-2}$ ). Peak accelerations were reached in the first few frames then steadily declined until the frame just before contact, when they were $44.5 \%$ of peak values.

\section{Post-strike phase}

The captured prey was not released, and immediately the snake began jaw movements leading to ingestion of the fish. If the jaws secured the fish on or behind the gills, then the jaws were lifted and moved independently by lateral stepping of the jaws toward the anterior end of the fish. Eventually the jaws worked the fish head into the snake's mouth, turning the fish so that the long axis of the fish was in line with the long axis of the snake's head. With the fish in this position, reciprocating displacements of the jaws marked the onset of swallowing (intra-oral transport). In the sequences that were scored, pilot studies and experimental trials $(n=198)$, swallowing was always head first. Only once did a snake swallow the fish tail first, and this was observed outside the trials, during normal maintenance feeding. Intraoral transport by reciprocating jaw displacements was by means of characteristic unilateral displacements (sensu Gans, 1961), also termed 'pterygoid walk' (sensu Boltt \& Ewer, 1964), to advance the jaws. This was similar to intra-oral transport described in terrestrial snakes (Cundall, 1983, 1987; Kardong, 1986).

The four small $(17.0-25.8 \mathrm{~cm}$ SVL) snakes were offered successively larger fish until they refused to strike or were unable to swallow and released the captured fish after several minutes. Swallowing of fishes near the upper size range often took $>5 \mathrm{~min}$. During such protracted swallowing, a snake occasionally $(n=3$ trials) lifted up to the surface of the water, still holding the partially swallowed large $(>6.5 \mathrm{~cm})$ fish securely in its mouth, and took a breath. The snake achieved this by rotating its head $180^{\circ}$, so the throat side was uppermost, and pushing the inverted throat above the surface of the water. The trachea was everted between the tips of the spread mandibles into the air, and the glottis was opened producing a patent route for breathing. After several minutes, the snake again submerged and resumed swallowing.

Often $(41.7 \%, 20 / 48)$ the tip of the prehensile tail was slowly twitched or undulated similar to what has been described as 'tail luring' (e.g. Heatwole \& Davison, 1976). However, these tail undulations were exhibited only after the strike, during swallowing, and usually $(80 \%, 16 / 20)$ when large $(>5 \mathrm{~cm})$ fish were being swallowed. These undulations involved just the tail tip, $c$. $1-$ $2 \mathrm{~cm}$, even if the base of the tail continued its prehensile hold. These undulations were intermittent and could persist until the fish reached the stomach.

After swallowing, a submerged snake exhibited occasional tongue flicks as it repositioned itself within the water column. Tongue flicking, also underwater, was observed in other behavioural contexts, such as before breaching the surface to breathe, or when disturbed during handling. The tongue flicks seemed to be similar to those of terrestrial snakes (e.g. Ulinski, 1972; Gove, 1979), wherein the narrow forked tongue was projected from the mouth, rapidly swept in a dorsoventral plane, then withdrawn back into the mouth.

\section{Swallowing}

In the four small snakes, all fish $(100 \%, n=48)$ were swallowed head first. For fish of similar sizes, handling was shorter than swallowing time. Handling averaged $17.0 \mathrm{~s}$ (fish <5cm: $7.7 \mathrm{~s}$, range $2-72 \mathrm{~s}$; fish $>5 \mathrm{~cm}: 24.9 \mathrm{~s}$, range 2-116 s); swallowing time averaged $236 \mathrm{~s}$ (fish $<5 \mathrm{~cm}$ : $44.7 \mathrm{~s}$ range $2-152 \mathrm{~s}$; fish $>5 \mathrm{~cm} 397.9 \mathrm{~s}$, range 62-2442 s). Both handling and swallowing times increased gradually with increasing fish size (Fig. 5). But at the upper limits of prey size, note that the variation and times increase substantially (Fig. 5).

\section{DISCUSSION}

The tentacled snake is specialized both in terms of its body features and its predatory behaviour, beginning with the tentacles themselves.

\section{Paired tentacles}

Some terrestrial snakes (e.g. Heterodon spp., Bitis gabonica) possess rigid upward-turned medial projections at 

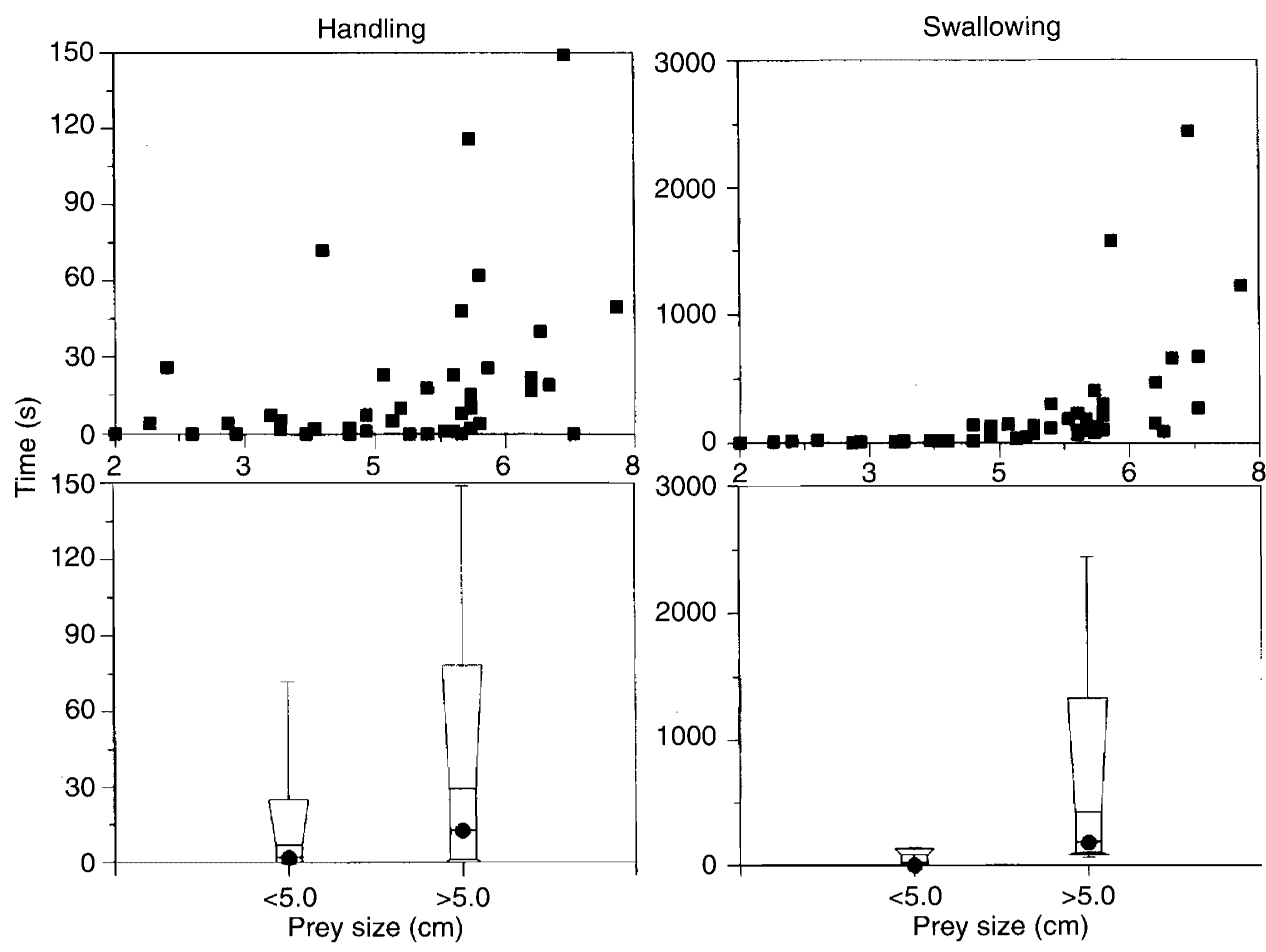

Fig. 5. Handling and swallowing times. All values recorded from four small snakes $17.0-25.8 \mathrm{~cm}$ snout-vent length, each snake taking part in about equivalent numbers of trials. Box-Whisker plots, actual distribution of the data; horizontal lines of a box plot mark the minimum and maximum, and the 10th, 25th, 50th, 75th, and 90th percentile points.

the tip of the snout, features thought to be related to leaf or loose soil turning behaviour (Kroll, 1976; Broadley, 1983). The arboreal snake Langaha is equipped with an unpaired long, projecting process from the snout. The paired fleshy tentacles of Erpeton, placed at the anterolateral corners of the snout, seem to be unique among snakes. During predatory behaviour, the tentacles were not moved or wiggled before the strike, even though they are composed of erectile tissue, highly innervated, and muscular (Winokur, 1977). Instead, the paired tentacles were held steady, projecting about $45^{\circ}$ from the corner of the snout. The foraging goldfish used mouth suction to gather up bits of food in the aquarium but showed no special interest in the tentacles, and did not attempt to feed on them. As the strike began, the tentacles collapsed immediately, falling back across the top of the head (Fig. 1b-d), presumably pushed back by the growing drag forces as the head accelerated. There may be a sensory role for the tentacles, pre-strike, wherein prey approach may produce advancing pressure waves detected by the projected tentacles. The collapsed tentacles have no tactile role during the strike, and we can conclude that the tentacles play no active role in attracting the attention of goldfish. Instead, these tentacles are more likely to be part of the snake's other behaviours, perhaps part of crypsis.

The body of Erpeton may be light reddish brown, sometimes patterned with paired spots (E. H. Taylor, 1965), or dark brown with light areas joining into dark stripes running along the body. The small, dorsoventrally compressed head continues on to a narrow neck that broadens posteriorly onto a generally wide body, which again narrows into a prehensile tail without bright or distinguishing colour. The coloration, stiff body, and slow movements are thought to provide effective crypsis, along with the tentacles that break up the linear snake shape (Hahn, 1973).

\section{Tail undulations}

Although the tail motion of Erpeton is reminiscent of 'tail luring' (e.g. Heatwole \& Davison, 1976), the tentacled snake deployed these in a different context. Tail luring generally occurs before the predatory strike and it is hypothesized to stimulate the approach of intended prey. In the tentacled snake, these slow tail twitches occurred after capture of the prey, during swallowing, and then mostly when swallowing was prolonged with large prey. If these were nervous twitches or inadvertent motions, then they might be expected during all swallowing events or in other contexts. However, we observed these only during swallowing of prey that was usually at the upper size range. The most promising hypothesis for this tail twitching behaviour is that it might divert the attention of the snake's own predators during swallowing, a time when the snake breaks its cryptic image, revealing that it is not an uninteresting stick, and is especially vulnerable to its predators. Therefore, the tail twitches are most likely diversionary, i.e. a defensive tail display (sensu Greene, 1973). 


\section{Swallowing behaviour}

As in other snakes, swallowing is unilateral (sensu Gans, 1961), proceeding by reciprocating displacements of the jaws along the swallowing axis (sensu Kardong, 1986) of the fish. Most strikes are to the anterior end of the fish, from whence stepping movements of the jaws begin immediately to bring them to the anterior end of the fish, where swallowing begins. The time taken to swallow the fish is directly proportional to fish size; the longer the fish, the longer it takes to be swallowed, until reaching an upper limit when fish are caught but rejected, or not struck at all. As the upper limits of fish size are reached, the swallowing times increase, and swallowing times become more variable. Although not directly measured, fish depth (dorsoventral height), which increases with length, seems to be the limiting dimension that directly prolongs swallowing rate as depth increases.

Swallowing of larger fish may take up to $30 \mathrm{~min}$ or more, an active time requiring breathing by the submerged snake. This is done without releasing the fish. The snake accomplishes this by rising to the surface, turning its head over one-half rotation, and lifting its protruded glottis above the surface of the water.

\section{Predatory behaviour}

The Erpeton predatory strike is different from all other snakes so far reported. The strike is not launched from body coils (e.g. Kardong \& Bels, 1998), nor does it exhibit mouth-open or lateral sweeping movements of its head (e.g. Gillingham, 1974; Jayne et al., 1988). Instead the strike occurs from a pre-set $\mathrm{J}$-shaped posture, with little evidence of adjustment of this posture to prey position. Although other species of snakes strike laterally (Kardong et al., 1997; Alfaro, 1998), none are known that commonly establish a fixed, pre-strike J-posture leading predominantly to lateral strikes.

\section{Aquatic specialist}

From such J-postures, Erpeton reached head accelerations underwater that were comparable to and often exceeded those recorded from terrestrial snakes (Janoo \& Gasc, 1992; Kardong \& Bels, 1998). We hypothesize that these accelerations are possible because Erpeton exhibits morphological and functional features that reduce the resisting drag forces during rapid displacement of the head through water.

In particular, Erpeton possess a shallow, dorsoventrally compressed skull (E. H. Taylor, 1965), a feature minimizing drag by reducing head profile through the water (M. A. Taylor, 1987). Further, the initial strike begins as a lateral sweep toward the prey, satisfying a prediction by Young (1991), that such a behaviour represents an aquatic specialization reducing the en- countered drag. However, by mid-strike, the opening jaws have turned toward the prey presenting a full frontal profile. Consequently, the oral area meeting the water increases substantially. If this water were displaced, this would increase drag forces proportionately (to area), resist the travel of the head to the prey, and slow its advance. Further, if at this point in the strike the head accelerated the water, then this would additionally add resisting forces to head acceleration (e.g. Daniel, 1984).

In the tentacled snake, these physical forces, which become more predominant in mid-strike as the snake turns toward the prey, are addressed by a simple specialization. The snake engulfs the water between itself and the prey. The volume of water between snake head and fish enters the snake's throat, inflating it. Water is therefore not displaced, pushed to the side, but simply engulfed, then expelled slowly after a successful capture. There was no evidence of significant suction feeding. Opening of the snake's jaws enlarged the gape to accommodate the fish, but no forces were generated sufficient to actually draw the fish into the buccal cavity. We therefore interpret the inflation of the throat as a passive event, not an active part of suction feeding. By engulfing much of this cone of water between the snake's head and the fish, the jaws move over this cone of water rather then through it, thereby reducing the drag forces that would otherwise resist travel of the head to the prey.

Further, throat inflation helps address the problem (M. A. Taylor, 1987) of pushing prey away upon approach or with expelled water during jaw closing. An aquatic predator approaching prey generates "bow waves', pressure waves that precede contact. If not deflecting prey directly, these can alert it to the imminent attack. By engulfing water before it, the tentacled snake reduces the forces it imparts to the water and thereby reduces the pressures that precede its contact with the prey. After a successful capture, this engulfed water is slowly expelled, the fish held by the teeth, thereby preventing this regurgitated water from dislodging the captured prey.

Terrestrial predators that enter aquatic environments meet physical demands that limit the effectiveness of terrestrial prey capture strategies (Vogel, 1982; M. A. Taylor, 1987; Denny, 1988; Liem, 1990). Functional and behavioural adjustments often compensate in water for morphological devices designed for service in air (M. A. Taylor, 1987), but this may not always occur. For example, suction feeding is especially effective for predators capturing prey in water, as it takes advantage of the viscosity of the fluid to gather in prey (Erdman \& Cundall, 1984; Lauder, 1985; Liem, 1990; Lauder \& Pendergast, 1992). However, some salamanders feeding underwater use tongue projection to capture prey (Schwenk \& Wake, 1988; J. H. Larsen, pers. comm.). This is surprising because lingual prehension of prey depends mainly upon wet adhesion, tongue to prey, which is most effective in air, but much less so in water (Bramble \& Wake, 1985). This represents limitations 
upon modification of design, and in a sense reveals constraints (sensu Schwenk, 1994) upon such adjustments to new environments.

Similarly within the tentacled snake, the features we have hypothesized to represent specializations for aquatic feeding are modifications of the basic snake bauplan, adaptive adjustments to rapid underwater strikes. The tentacled snake does not feed by means of generated suction, a feature requiring a heavily muscularized jaw apparatus that expands the buccal cavity. Instead, the features are modifications of features that are already part of the basic terrestrial snake design.

\section{Acknowledgements}

We thank the Fort Worth Zoo for supplying us with snakes, Lisa Teodecki for the donation of her Erpeton, and John H. Larsen $\mathbf{J r}$ for discussion of amphibian feeding.

\section{REFERENCES}

Alfaro, M. E. (1998). Striking and sweeping: prey capture in thamnophiine snakes. Am. Zool. 38: 11A.

Alexander, R. M. (1983). Animal mechanics. London: Oxford: Blackwell Scientific Publications.

Boltt, R. E. \& Ewer, R. F. (1964). The functional anatomy of the head of the puff adder, Bitis arietans. J. Morphol. 114: 83-103.

Bramble, D. M. \& Wake, D. B. (1985). Feeding mechanisms of lower tetrapods. Cambridge, MA: Belknap Press.

Braun, T. B. \& Cundall, D. (1995). Hydrodynamics of fishing in snakes (Nerodia). Am. Zool. 35: 105A.

Broadley, D. G. (1983). Fitzsimons' snakes of southern Africa. Johannesburg: Delta Books.

Cock Buning, T. D. (1983). Thermal sensitivity as a specialization for prey capture and feeding in snakes. Am. Zool. 23: 363-375.

Cundall, D. (1983). Activity of head muscles during feeding by snakes: a comparative study. Am. Zool. 23: 383-396.

Cundall, D. (1987). Functional morphology. In Snakes - ecology and evolutionary biology: 106-142. Seigel, R. A., Collins, J. T. \& Novak, S. S. (Eds). New York: Macmillan Press.

Daniel, T. L. (1984). Unsteady aspects of aquatic locomotion. Am. Zool. 24: 121-134.

Denny, M. W. (1988). Biology and the mechanics of the wave-swept environmenst. Princeton, NJ: Princeton University Press.

Drummond, H. M. (1983). Aquatic foraging in garter snakes: a comparison of specialists and generalists. Behaviour 86: 1-30.

Erdman, S. \& Cundall, D. (1984). The feeding apparatus of the salamander Amphiuma tridactylum: morphology and behavior. J. Morphol. 181: 175-204.

Fitch, H. S. (1949). Study of snake populations in central California. Am. Midl. Nat. 41: 513-579.

Fitch, H. S. (1965). An ecological study of the garter snake, Thamnophis sirtalis. Univ. Kans. Publ. Mus. Nat. Hist. 15: 493-564.

Gans, C. (1961). The feeding mechanism of snakes and its possible evolution. Am. Zool. 1: 217-227.

Gans, C. \& Taub, A. (1964). Precautions for keeping poisonous snakes in captivity. Curator 7: 196-205.

Gillingham, J. C. (1974). Notes on the fishing behavior of water snakes. J. Herpetol. 8: 384-385.

Gove, D. A. (1979). Comparative study of snake and lizard tongue-flicking with an evolutionary hypothesis. Z. Tierpsychol. 51: 58-76.

Greene, H. W. (1973). Defensive tail display by snakes and amphisbaenians. J. Herpetol. 7: 143-161.

Gregory, P. (1978). Feeding habits and diet overlap of three species of garter snakes (Thamnophis) on Vancouver island. Can. J. Zool. 56: 1967-1974.

Hahn, D. E. (1973). Comments on tentacle structure and function in Erpeton tentaculatum (Serpentes: Colubridae). J. Herpetol. 7: 304-306.

Halloy, M. \& Burghardt, G. M. (1990). Ontogeny of fish capture and ingestion in four species of garter snakes (Thamnophis). Behaviour 112: 299-318.

Hayes, W. K. (1991). Envenomation strategies of prairie rattlesnakes, $\mathrm{PhD}$ University of Wyoming, Laramie, WY.

Heatwole, H. (1987). Sea snakes. Kensington, NSW, Australia: New South Wales University Press.

Heatwole, H. \& Davison, E. (1976). A review of caudal luring in snakes with notes on its occurrence in the Saharan sand viper, Cerastes vipera. Herpetologica 32: 332-336.

Janoo, A. \& Gasc, J.-P. (1992). High speed motion analysis of the predatory strike and flurographic study of oesophageal deglutition in Vipera ammodytes: more than meets the eye. Amphib.Reptilia 13: $315-325$.

Jayne, B. C., Voris, H. K. \& Heang, K. B. (1988). Diet, feeding behavior, growth, and numbers of a population of Cerbeus rynchops (Serpentes: Homalopsinae) in Malaysia. Fieldiana Zool. 50: 1-15.

Kardong, K. V. (1986). Kinematics of swallowing in the yellow rat snake, Elaphe obsoleta quadrivittata: a reappraisal. Jpn. J. Herpetol. 11: 96-109.

Kardong, K. V. \& Bels, V. L. (1998). Rattlesnake strike behavior: kinematics. J. exp. Biol. 201: 837-850.

Kardong, K. V., Kiene, T. L. \& Johnson, E. K. (1997). Proximate factors affecting the predatory behavior of the red spitting cobra, Naja mossambica pallida. J. Herpetol. 31: 66-71.

Kroll, J. C. (1976). Feeding adaptations of hognose snakes. Southwest. Nat. 20: 537-557.

Kropach, C. (1975). The yellow-bellied sea snake, Pelamis, in the eastern Pacific. In The biology of sea snakes: 185-213. Dunson, W. A. (Ed.). Baltimore, MD: University Park Press.

Lauder, G. V. (1985). Aquatic feeding in lower vertebrates. In Functional vertebrate morphology: 210-229. Hildebrand, M., Bramble, D. M., Liem, K. F. \& Wake, D. B. (Eds). Cambridge, MA: Harvard University Press.

Lauder, G. V. \& Pendergast, T. (1992). Kinematics of aquatic prey capture in the snapping turtle Chelydra serpentina. J. exp. Biol. 164: 55-78.

Liem, K. F. (1990). Aquatic versus terrestrial feeding modes: possible impacts on the trophic ecology of vertebrates. Am. Zool. 30: 209-221.

Madsen, T. \& Osterkamp, M. (1982). Notes on the biology of the fish-eating snake Lycodomorphus bicolor in Lake Tanganyika. J. Herpetol. 16: 185-188.

Mori, A. (1998). Prey-handling behavior of three species of homalopsine snakes: features associated with piscivory and Duvernoy's glands. J. Herpetol. 32: 40-50.

Mushinsky, H. R. \& Hebrard, J. J. (1977). Food partitioning by five species of water snakes in Louisiana. Herpetologica 33: 162-166.

Savitzky, B. A. (1992). Laboratory studies on piscivory in an opportunistic predator, the cottonmouth, Agkistrodon piscivorus. In Biology of the pitvipers: 347-368. Campbell, J. A. \& Brodie, E. D. Jr (Eds). Tyler, TX: Selva.

Schwenk, K. (1994). A utilitarian approach to evolutionary constraint. Zoology, Analysis Complex Ssytems (Zool.) 98: 251-262.

Schwenk, K. \& Wake, D. B. (1988). Medium-independent feeding in a plethodontid salamander: tongue projection and prey capture under water. Am. Zool. 28: 115A. 
Shine, R. (1977). Habitats, diets, and sympatry in snakes: a study from Australia. Can. J. Zool. 55: 1118-1128.

Shine, R. (1986). Ecology of a low-energy specialist: food habits and reproductive biology of the Arafua filesnake (Acrochordidae). Copeia 1986: 427-437.

Smith, M. A. (1943). The fauna of British India, Reptilia and Amphibia. London: Taylor \& Francis.

Taylor, E. H. (1965). The serpents of Thailand and adjacent waters. Univ. Kans. Sci. Bull. 45: 609-1096.

Taylor, M. A. (1987). How tetrapods feed in water: a functional analysis by paradigm. Zool. J. Linn. Soc. 91: 171-195.

Ulinski, P. S. (1972). Tongue movements in the common boa (Constrictor constrictor). Anim. Behav. 20: 373-382.
Vogel, S. (1982). Life in moving fluids. Princeton, NJ: Princeton University Press.

Voris, H. K. \& Voris, H. H. (1983). Feeding strategies in marine snakes: an analysis of evolutionary, morphological, behavioral and ecological relationships. Am. Zool. 23: 411-425.

Voris, H. K., Voris, H. H. \& Lim, G. L. (1978). The food and feeding behavior of a marine snake, Enhydrina schistosa (Hydrophiidae). Copeia 1978: 134-146.

Winokur, R. M. (1977). The integumentary tentacles of the snake Erpeton tentaculatum: structure, function, evolution. Herpetologica 33: 247-253.

Young, B. A. (1991). The influences of the aquatic medium on the prey capture system of snakes. J. nat. Hist. 25: 519-531. 